\title{
Kinship and intimacy
}

\author{
Hugh LaFollette
}

Department of History and Politics, University of South Florida St. Petersburg hughlafollette@gmail.com

DOI: http://dx.doi.org/10.5324/eip.v11i1.2244

(cc) BY This is an open access article distributed under the terms of the Creative Commons Attribution 4.0 International License, which permits unrestricted use, distribution, and reproduction in any medium, provided the original author and source are credited.

We think about personal relationships in two distinct ways. The first focuses on relationships between blood relatives: parents and their children, siblings, and perhaps first cousins. The second focuses on intimacy: relationships where each individual is honest to and trusting of the other; each cares for the other and seeks the other's company. In this article I ask how these two conceptions are, can be, or should be linked. Should we strive to make all relationships with kin intimate? Even if the answer is a qualified "No," does that mean relationships with kin are not valuable? I offer some tentative answers to these questions. Despite its limitations, I hope this provides a framework from which future exploration of these issues might profitably begin.

Keywords: kinship, intimacy, trust, honesty, caring, family, friends, spouses

When people think about personal relationships, many commonly think of those between blood relatives: parents and their children, siblings, and perhaps first cousins. They think that persons so related do, or at least should, care for and assist one other. I call this the "kinship view" of personal relationships.

Many people also construe personal relationships in terms of intimacy: each individual shares revealing information about her wishes, desires, and deeper disposing traits with the other; each trusts, is honest with, and cares for the other. Each likes the other for who they are, not because of some image of what they want the other to be. Each seeks - and enjoys - the other's company (LaFollette 1996, Chapter 7, LaFollette and Graham 1986). I call this the "intimacy view."

Although most of us consider both of these to be different forms of personal relationships, there has been remarkably little discussion about how, if at all, these two conceptions are related. It is not just remarkable - it is more than a bit worrisome. I believe that we should understand how kinship and intimacy (so defined) are, can be, or should be linked. My proposals here are little more than suggestions. However, I think it is worth trying to propose a framework within which future exploration might profitably begin.

I suggest that the following claims capture interconnections between kin and intimate relationships, at least within most modern Western democracies.

- Not every intimate relationship is a relationship with kin. People are often intimate with their spouses or partners and with their closest friends. These latter forms of relationships arose voluntarily, since they are not blood-based. 
- Not all kin relationships are intimate. Not only are many not intimate, a number are not close in any relevant sense. A significant number of people are estranged from - or even antagonistic towards - some kin. A few parents and their grown children do not acknowledge one another. Siblings may avoid one another, at least when they can do so without being too blatant. Cousins may rarely interact.

- Some people (and some groups of people) cherish their kin, and they do so automatically, without much thought. However, people may cherish their kin without being intimate with them in ways they might be intimate with a partner or a close friend. Other kin may be close with some kin, and they may be intimate to some degree.

The issue is whether these observations capture not only current practice but also the way things should be. Is a frequent lack of intimacy among kin something we should bemoan? Barring special reasons to the contrary, should each of us pursue intimacy with our parents, grown children, siblings, or cousins? Should our society encourage kin to be intimate with one another? Or would all such efforts be morally misguided?

Perhaps in asking these questions we are erroneously assuming there is a onesize-fits-all answer: that kin should (or should not) standardly be intimate with their parents, children, siblings, and perhaps even some cousins. The more plausible answer may well be simpler: some are and some are not; some should be and some should not be. From this perspective, healthy kin relationships commonly promote certain goods, while healthy intimate relationships promote others. Although both types of relationships may be necessary parts of a fulfilling life, the two forms need not always - or even often - coexist.

Although the inquiry may end here, I do not think that it is a suitable place for it to begin. After all, in many cultures, close relationships with kin are pursued and prized. In some, these relationships have elements of genuine intimacy. Even in more western and less family-oriented cultures, having intimate relationships with one's kin is often lauded, even if relatively infrequently achieved.

A fourth observation about kinship and intimacy captures the degree to which many families aspire to such intimacy:

- Many, and probably most, of us would like to be somewhat intimate with our parents or grown children. We want to be honest with them and they with us. We want to reveal who we really are; we want to know who they really are. We want to revel in their company. This is an ideal for which many of us yearn, even if we know that we are unlikely to attain it.

That said, although this is an aspiration for many of us, some people find the ideal of intimacy with one's children or parents odd. For these people, parents love their grown children and want their children to respect them; they also may want to be close in a sense defined shortly. They would not want to be intimates, at least not with their children, and perhaps not with siblings or cousins.

\section{Closeness vs intimacy}

The fourth observation suggests some relevant differences between closeness and intimacy. I earlier defined an "intimate relationship" as one in which each individual a) regularly shares revealing information about her wishes, desires, and 
deeper disposing traits with the other; b) each party likes the other for who she is; $c$ ) each party trusts and is honest with and d) cares for the other, and e) each seeks and enjoys - the other's company. Intimacy so defined is a rare achievement. In its most robust form, it may even be relatively rare among partners. We all know many partners and friends who are selectively honest or selectively trusting.

This is even more common in relationships between kin. Most of us know (or are) grown children who have relationships with their parents that are less honest and trusting than one's relationships with moderately intimate friends. In many relationships between parents and children and between grown siblings, certain topics are never broached, certain ways of expression are off-limits, or some actions are taboo. Nonetheless, the parents care for and are willing to assist their children, and vice versa. Often, each wants to spend at least some time with the other. To some degree, they enjoy one another's company. In these respects, these relationships have several, albeit attenuated, elements of intimacy. That they are attenuated should not be entirely surprising, since the relationships are defined by blood, not by the fact that each person likes or respects the other.

We can better understand why many kin relationships are not fully intimate once we grasp that while kinship is determined immediately upon birth, intimate relationships do not appear fully formed and all at once. These emerge in stages and over time. Individuals may have particular intimate exchanges, that is, occasions in which they reveal something deep and important about themselves to another. In so doing, they exemplify some measure of trust in the other. However, single or even multiple intimate exchanges do not an intimate relationship make.

Since intimacy, like other traits, is an achievement and not a given, we can see why kin relationships are not automatically intimate, and why many are unlikely to become so. Simply being around another person regularly does not guarantee intimacy, not even in an attenuated form. Indeed, some features of kin relationships can be obstacles to more intimate relationships. For instance, when children are young, parents are authority figures. In this role, parents are often not fully honest with their children nor do they trust them. Usually, the reverse is also true. After a while, both parents and their children become accustomed to relating to each other in these ways. They habitually relate to each other as parents or as children. That history may make it difficult for them to adjust their roles and style of relating. It is often difficult for them to become completely honest and trusting with the other. Or, if siblings were rivals growing up, they may find it difficult to get past whatever ill feelings they have toward one another. Of course some people may be able to move past these historical obstacles.

I suspect these family histories explain why many relationships between parents and their grown children are close but not intimate. Indeed, closeness with kin is the most that many of us can plausibly aspire to. That does not show that non-intimate kin relationships are worthless; they are often very valuable. Parents typically care for their children and children often care for their parents. Often the same is true with siblings. Being close with one's parents and grown siblings can be enjoyable, meaningful, and valuable. Each may occasionally want to be around the other, although usually not for long and usually not to the degree they would want to be, were they in a full-fledged intimate relationship. Nor do they enjoy each other's companionship in the ways or to the degree that intimates do. Certainly, kin are often not as honest or as trusting as intimates standardly are. It is not that these kin 
are wholly dishonest or that they do not trust the other at all. However, usually kin are guarded around one another, so the scope for full intimacy is limited. Nonetheless, healthy relationships with kin are often deeper and more valuable than those with mere acquaintances.

We need a way of describing healthy versions of these important, even if not wholly intimate, relationships. Calling them "close relationships" is accurate, descriptive, and true to common usage.

I think it is a mistake to discuss close and intimate relationships with kin in a historical vacuum. So, I want to briefly examine ways that relationships with kin have evolved over time.

\section{How kin relationships have changed}

For much of human history, extended families (and clans or tribes) played a central role in rearing children and in caring for one another. The extended family was the focus of human interaction. Most people lived with or near their parents; thus, siblings were typically in a position where they interacted with their parents and with one another, and often with grandparents and cousins. These relationships provided essential forms of human contact. Within such an environment, it was not unusual for kin to be close and sometimes intimate.

However, the world has changed. What was once the norm is now relatively unfamiliar. People today are far more mobile. Although some grown children stay geographically close to their parents, at least middle class children within modern democracies are far more likely to move away from the city of their birth. Then, as they start their own families, the frequency and intensity of their interactions with parents, siblings and cousins usually diminishes. For distant relatives, contact usually comes during major holidays, if it comes at all. If people relate with kin more often and more deeply than that, it is because both parties have made special efforts to build and maintain the relationship.

In this new environment, most people are no longer as dependent on their parents, children or siblings for human interaction. Given that, it is not surprising that kin relations tend to be less close, and are even less likely to be intimate. Nonetheless, in times of serious need - e.g. extended illness, especially at the end of life - people often need help, and when they do, they frequently call on family. Their kin may well respond, even if they have not been especially close in the past. The mere fact that kin come to one another's aid suggests that they are close enough: they care for one another. This relationship might most accurately be characterized as a familial form of civic friendship (Aristotle 1984, The Politics). Although valuable, this should not be taken as proof of genuine intimacy.

These cases, and the social changes that have altered the familial landscape, largely explain why kin often are not fully intimate. They also identify ways in which such relationships are valuable, even if non-intimate. Kin relationships are the default way by which people gain their initial experience relating to others. They may even provide some reason why we should seek to be intimate with some kin. 


\section{Why people should be intimate-or at least close-with kin}

Many who argue that kin should - generally - be at least somewhat intimate with each other often talk as if this impulse were a biological imperative. Three main options capture this view, although the third option itself takes three distinct forms. We can place all five options along a continuum.

- Kin intimacy is a natural instinct: when kin relationships are not intimate or close, it is because something has gone awry.

- Kin intimacy is a natural proclivity, or what we might dub a "weak instinct." Although it is a proclivity people can and do shake, in general, we would be better off not doing so. We should at least be close, and preferably intimate, with some kin.

- According to the remaining options, the impetus to be close, or even intimate with one's kin, is compatible with human nature, but it is neither an instinct nor a proclivity.

- Some compelling reasons exist for promoting intimacy with kin when feasible, although it might be ill advised in individual cases.

- There is nothing especially laudatory about trying to be close or intimate with one's kin.

- There is nothing wrong with being intimate with one's kin, and it might even he valuable when it happens. However, more often than not, striving for intimacy - and perhaps closeness - with kin is a vain hope, which, even if achieved, often comes at considerable cost.

Why might some people embrace the idea that intimacy with kin is an instinct or at least a proclivity? The claim likely springs from the evolutionary notion of kin selection (Smith 1964, Sober and Wilson 1998), that there is a strong biological impulse to favor one's close genetic kin. Indeed, some say kin selection is proportionally as strong as the impulse to favor oneself: that the biological imperative to save two of one's biological children (each with half of the parent's DNA) is as strong as for the parent to save herself.

However, even traits with evolutionary origins can be, and often are, appropriately constrained by moral and cultural norms. We may well be instinctively prone to jealousy, revenge, violence, and fear of the unfamiliar. These proclivities may have arisen because they served our ancestors well. However, instincts and proclivities that once served humans well may no longer be beneficial in our current world. We have government, formal education, and parental instruction whose aim, at least in part, is to constrain some of our baser impulses. The real issue, then, is whether a prima facie case even exists for thinking that kin intimacy is something we should seriously pursue.

It is difficult to imagine the view that being close or intimate with one's kin is never valuable. However, more often than we dare admit, people are not close or intimate with their parents or siblings, let alone more distant kin. The issue is not whether it is ever beneficial to be close or intimate with a parent or grown child or sibling. The issue is rather how often kin intimacy is, or could be, beneficial and whether it is sufficiently valuable to vigorously pursue it. What are the potential benefits and downsides of having or expecting or pursuing closeness or intimacy with a parent or grown sibling? 


\section{The nature of kinship}

Healthy kin relationships may be close, and they may even approximate a fully intimate relationship. However, even being close may be more than adequate to meet some of people's vital social needs. We need not assume that the only valuable relationships are fully intimate. Even a relationship that is merely close may be valuable in itself: it provides and encourages valuable social interactions (Baumeister and Leary 1995) that, as mentioned earlier, may become an important means of providing assistance in times of need. These interactions may also provide an environment in which a kin relationship could become close or even intimate.

Although kin may start out spending time together because of their blood relationships, eventually their proximity and regular contact may help them become close or even intimate. If so, then what holds them together has morphed from a relationship defined by blood into one defined by shared experiences and history. Having a common history - whether pleasant or traumatic - can be a source of closeness. Kin (and old friends) often share common, enjoyable experiences, such as eating meals, playing card games or golf, walking through the woods, or watching a sunset. After a while, shared stories of previous experiences become their own kinship glue. Recalling experiences can prompt raucous laughter, soothing memories, or melancholia. These experiences and recollections may not reflect a robust intimacy. However, they do encourage kin to keep in contact with one other and to provide each other with ongoing sources of enjoyment. Sharing traumatic experiences, such as siblings who comfort one another after the early and untimely death of a parent, can also encourage closeness and often intimacy. People facing loss or death may become incredibly close. This is a well-documented phenomenon among comrades in arms (Gray 1998/1958, Chapter 2).

These features of kinship may create and sustain what could well become a close, and perhaps an intimate, relationship. People with shared experiences have something in common that makes it more likely that they will enjoy each other's company. If two people already enjoy one other's company, and each has traits that the other finds valuable or attractive, the impetus grows for them to spend even more time together, to trust one another, and to begin to selectively share more about themselves, their desires, and who they are. In short, these shared experiences are an impetus to closeness or intimacy.

These possibilities should not surprise us. We usually meet our eventual partners and our close friends in an environment where we are thrust together for some nonintimate purpose. In these conditions, we share experiences, and - in the case of war or sometimes work - we face a common enemy. This environment does not guarantee intimacy, whether among kin or non-kin. However, some shared experiences are necessary causal conditions for closeness and intimacy. Once the bonds begin to form, the same environment can enable and sustain them. Every genuinely intimate relationship has non-intimate beginnings. Some external factor brings people together: work, playing on a sports team, or trying to promote what they deem a significant cause.

\section{Intimacy is not self-sustaining}

However, close and intimate relationships are not self-sustaining. Admittedly, some relationship inertia may play a role. If two people are already close, they will likely 
spend more time together and thus be in an environment that makes continuing the relationship more probable; certainly it will be easier to maintain. However, life can get in the way of continuing closeness or intimacy and make losing touch inevitable or even highly likely. There are people with whom I was once intimate when we were in college or graduate school. Although we built a legacy of trust and intimacy, many of those relationships declined after one of us moved to a different town, got married or changed jobs within the same town. Something similar happened with some professional colleagues with whom I was once intimate. We should not be surprised. Relationships are not static objects but ongoing processes. Keeping a relationship strong requires time and effort.

Even spouses, partners, or close friends can "grow apart. Without serious and continuing effort, people living under the same roof may cease to be intimate (LaFollette 1996, Chapter 12).

\section{Why we should not try to regularly link intimacy and kinship}

Although acknowledging the benefits of being close, or even intimate, with some kin, I would also note the potential drawbacks of trying to wed kinship and intimacy. Understanding the different origins of each can help us see why. We may eventually become close with fellow students or colleagues. However, although accident threw us together, choice keeps us together. We liked what we did with and saw in the other; we each chose to further pursue the relationship. The situation is different with kin. We do not choose our parents, children, siblings, or cousins. We are connected to them through no choice of our own. Whereas we at least partly choose our friends or partners, we are stuck with our kin. Sometimes we may not like them. Other times, we may not actively dislike them, but neither do we especially wish to be around them often. We may also fear being honest with them. In these cases, trying to become intimate, or even close, may backfire.

In most relationships with kin, certain topics are off limits. Thus, at large family dinners growing up in my family, we were not supposed to talk about religion (other than the perfunctory prayer before eating), and especially not politics. Since many people care deeply about their religion (or lack of it) and their political views, this taboo means that an array of important topics cannot be addressed. Hence, it is not surprising that in an environment where we must watch our every word, lest we offend another member of the extended family, people are unlikely to be close and even less likely to be intimate. It is not pleasant to be around others, knowing that one must always be on constant intellectual and emotional guard. In short, kin relationships often exclude key elements of intimacy. It is thus unsurprising that kin relations are many times non-intimate. In addition, expending considerable energy in trying to be close to kin may take time away from more satisfying and important genuinely intimate relationships.

That said, indirect benefits might encourage us to spend some time with kin and to try to be close despite our differences. After all, we may not like some of our fellow students or colleagues, but circumstances require that we relate to them. In general, it is better if most of our relationships can be civil, and preferably somewhat enjoyable. Having to relate with kin we don't especially care for, and would never choose to spend time with otherwise, can help us develop the ability to relate 
fruitfully with other people we dislike. In that way, kin relationships can prepare us for life and for employment in our world.

Of course, it likely would not thrill our kin to know that our challenging social interactions with them serve as a means to developing some valuable social trait. Hence, although this may be a valuable knock-on effect of such relationships, we should think of it as an unintended consequence and not the rationale for trying to be close.

\section{Conclusion}

What we have seen is that there are benefits of having some close, and even intimate, relationships with kin. Moreover, there are ways in which relating to kin can encourage closeness and intimacy. At the same time, straining to make most kin relationships close or intimate has its costs. In short, we seem to end up with the simpler conclusion mentioned, and then temporarily dismissed, at the beginning of the paper. Sometimes being close or intimate with kin is beneficial and sometimes it is not. Sometimes we should strive for it and sometimes we should not. Nonetheless, although we end up in a similar position, I would posit that we are better off by understanding why this approach is both prudent and moral.

I am inclined to think we should neither wed nor divorce kinship and intimacy. As long as attempts to be close with kin do not require herculean effort, making some effort is fine and perhaps wise. Healthy kin relationships can be highly valuable, and even close. However, individuals should be free not to pursue closeness or intimacy, especially if they find that their efforts have been less than satisfactory. They might do better to just be supportive of kin without pursuing intimacy.

\section{References}

Aristotle. 1984. The Complete Work of Aristotle, The Politics. Princeton, N.J: Princeton University Press.

Baumeister, Roy F, and Mark R Leary. 1995. "The need to belong: desire for interpersonal attachments as a fundamental human motivation." Psychological bulletin 117 (3):497. https://doi.org/10.1037/0033-2909.117. 3.497

Gray, J. Glenn. 1998/1958. The Warriors: Reflections on Men in Battle. Lincoln, NE: University of Nebraska Press.

LaFollette, Hugh. 1996. Personal Relationships: Love, Identity, and Morality. Oxford: Blackwell Publishers.

LaFollette, Hugh, and George Graham. 1986. "Honesty and Intimacy." Journal of Social and Personal Relationships 3:3-18. https://doi.org/10.1177/ 0265407586031001

Smith, John Maynard. 1964. "Group Selection and Kin Selection." Nature 201 (4924):1145-47. https://doi.org/10.1038/2011145a0

Sober, Elliott, and David Sloan Wilson. 1998. Unto Others: The Evolution and Psychology of Unselfish Behavior. Cambridge, MA: Harvard University Press. 